\title{
Time course of fluid responsiveness in sepsis: the fluid challenge revisiting (FCREV) study
}

\author{
Claire Roger ${ }^{1,2}$, Laurent Zieleskiewicz ${ }^{3,11}$, Christophe Demattei ${ }^{4}$, Karim Lakhal ${ }^{5}$, Gael Piton ${ }^{6}$, Benjamin Louart ${ }^{1,2}$, \\ Jean-Michel Constantin ${ }^{7}$, Russell Chabanne ${ }^{7}$, Jean-Sébastien Faure ${ }^{7}$, Yazine Mahjoub $^{8}$, Isabelle Desmeulles ${ }^{9}$, \\ Hervé Quintard ${ }^{10}$, Jean-Yves Lefrant ${ }^{1,2}$, Laurent Muller ${ }^{1,2^{*}}$ and AzuRea Group
}

\begin{abstract}
Background: Fluid challenge (FC) is one of the most common practices in Intensive Care Unit (ICU). The present study aimed to evaluate whether echocardiographic assessment of the response to FC at the end of the infusion or 20 min later could affect the results of the FC.

Methods: This is a prospective, observational, multicenter study including all ICU patients in septic shock requiring a FC of $500 \mathrm{~mL}$ crystalloids over $10 \mathrm{~min}$. Fluid responsiveness was defined as a $>15 \%$ increase in stroke volume (SV) assessed by velocity-time integral $(V T I)$ measurements at baseline $\left(T_{0}\right)$, at the end of FC $\left(T_{10}\right)$, then $10\left(T_{20}\right)$ and 20 $\min \left(T_{30}\right)$ after the end of FC.

Results: From May 20, 2014, to January 7, 2016, a total of 143 patients were enrolled in 11 French ICUs (mean age $64 \pm 14$ years, median IGS II 53 [43-63], median SOFA score 10 [8-12]). Among the 76/143 (53\%) patient responders to FC at $T_{10}, 37$ patients were transient responders (TR), i.e., became non-responders (NR) at $T_{30}(49 \%, 95 \% \mathrm{Cl}=[37-60])$, and $39(51 \%, 95 \% \mathrm{Cl}=[38-62])$ patients were persistent responders (PR), i.e., remained responders at $T_{30}$. Among the $67 \mathrm{NR}$ at $T_{10}, 4$ became responders at T30, $(6 \%, 95 \% \mathrm{Cl}=[1.9-15.3])$. In the subgroup analysis, no statistical difference in hemodynamic and echocardiographic parameters was found between groups.
\end{abstract}

Conclusions: This study shows that $51.3 \%$ of initial responders have a persistent response to fluid 30 min after the beginning of fluid infusion and only $41.3 \%$ have a transient response highlighting that fluid responsiveness is time dependent.

Trial registration: ClinicalTrials.gov, NCT02116413. Registered on April 16, 2014

Keywords: Fluid responsiveness, Fluid challenge, ICU, Shock, Echocardiography

\section{Background}

Fluid therapy is the primary resuscitation maneuver of acute circulatory failure management in critically ill patients [1]. Adequate fluid resuscitation is a key issue as both hypovolemia and fluid overload are associated with poor outcome in intensive care unit (ICU) [2-4]. Despite consistent data published over the last decades,

\footnotetext{
* Correspondence: laurent.muller@chu-nimes.fr

${ }^{1}$ Department of Anesthesiology and Intensive Care, Pain and Emergency Medicine, Nîmes-Caremeau University Hospital, Univ Montpellier, Place du Professeur Robert Debré, 30029 Nîmes Cedex 9, France

${ }^{2}$ Physiology Department. EA 2992, Faculty of Medicine, Univ Montpellier, Montpellier-Nimes University, Nîmes, France

Full list of author information is available at the end of the article
}

the criteria indicating fluid administration remains highly debated [5-7]. Recent large observational studies have shown that ICU physicians mainly use arterial pressure and heart rate to assess blood volume status, while measurement of cardiac output (CO) or stroke volume (SV) is rarely performed $[8,9]$. Even so, the goal of fluid infusion is to increase SV or CO when hypovolemia or preload dependency is suspected. As CO (or its surrogates) better describes blood volume variations than arterial pressure and heart rate $[1,10]$, international guidelines recommend measuring $\mathrm{SV}$ or $\mathrm{CO}$ to evaluate fluid status in patients that are not responding to initial resuscitation based on clinical assessment [1, 10]. A

(c) The Author(s). 2019 Open Access This article is distributed under the terms of the Creative Commons Attribution 4.0 International License (http://creativecommons.org/licenses/by/4.0/), which permits unrestricted use, distribution, and 
positive response to fluid therapy (fluid responsiveness) is defined as a $10-15 \% \mathrm{SV}$ or CO increase immediately after 250 to $500 \mathrm{ml}$ of fluid infusion $[1,11]$. In ICU, transthoracic Doppler echocardiography (TTE) provides a non-invasive estimation of $\mathrm{SV}$ by measuring the velocity time integral (VTI) of sub-aortic blood flow $[1,7,12]$. A $15 \%$ VTI increase is used to define fluid responders [1, 12, 13].

Beyond immediate response to fluid infusion, the efficacy of a fluid bolus over time is affected by various parameters such as blood volume status, cardiac function, type of infused fluid, and capillary leak severity [14]. Little data is available to describe the time course of fluid efficacy defined as a greater than 15\% CO increase. It could be hypothesized that, after a fluid bolus, the initial $\mathrm{SV}$ or CO increase could not be sustained over time. Therefore, we could imagine that a patient initially identified as a fluid responder could no longer be responder 30 min after fluid infusion, leading to discrepancies in fluid management decision-making.

The primary aim of the present study was to determine the proportion of patients changing from a responder status immediately after a 10-min fluid infusion to a non-responder status $20 \mathrm{~min}$ after the end of infusion.

\section{Methods}

We conducted a prospective multicenter study involving 11 intensive care units (ICUs) in 8 University Hospitals (Nimes, Marseille, Nice, Clermont-Ferrand, Nantes, Caen, Amiens, Besancon). The protocol was approved by the Nimes University Hospital local ethics committee (Comité de Protection des Personnes \#2014.02.06, \#ID_RCB 2013-A01702-43) and registered in ClinicalTrials.gov (NCT02116413). Written consent prior to enrolment or in permitted instances, delayed participant or legal surrogate written consent following enrolment was obtained.

\section{Participants}

Adult ICU patients meeting criteria for septic shock and requiring a fluid challenge according to the treating physician were eligible for inclusion.

The inclusion criteria were:

- Patient $\geq 18$ year old who gave his (her) informed consent (or his (her) relative) or delayed

- Patient with septic shock according to the Surviving Sepsis Campaign criteria [15]

- Patient on mechanical ventilation without spontaneous breathing

- Patients in whom a fluid challenge was required for the following reasons, according to physician decision:

- Persistent hypotension despite fluid resuscitation of 20 to $40 \mathrm{~mL} / \mathrm{kg}$ and requiring vasopressors as indicated in 2012 Surviving Sepsis Campaign

criteria [15]

- $\mathrm{ScVO}_{2}<70 \%$ or $\mathrm{SvO}_{2}<65 \%$.

- Urine output $<0.5 \mathrm{~mL} \mathrm{~h}^{-1}$ during two consecutive hours

- Skin mottles

- Arterial lactate concentration $>2 \mathrm{mMol} \mathrm{L}^{-1}$

Non-inclusion criteria were:

- Informed consent not obtained

- Prisoner

- Patient under legal guardianship

- Parturient

- Severe mitral or aortic regurgitation

- Patients with cardiac arrhythmia

- Poor echogenicity

Exclusion criteria were patients in whom a new fluid challenge was required or requiring an increase in vasopressor infusion rate before the end of the protocol.

\section{Study protocol}

Intervention, fluid responsiveness definition (Fig. 1)

Included patients were monitored with invasive arterial pressure. The fluid challenge was performed with 500-ml crystalloids $(0.9 \% \mathrm{NaCl}$ or lactated Ringer's) over $10 \mathrm{~min}$ at a constant infusion rate $\left(50 \mathrm{ml} \mathrm{min}^{-1}\right)$. Fluid responsiveness was defined as a $>15 \%$ increase in SV [1].

\section{Measured parameters and time of measurement}

The different studied parameters were collected from baseline $\left(T_{0}\right)$ just before the initiation of fluid challenge until $20 \mathrm{~min}\left(\mathrm{~T}_{30}\right)$ after the end of fluid challenge. This timing was chosen as fluid challenge is classically performed in 10 to $30 \mathrm{~min}[11,16]$. Exploring the effect of fluid challenge after $T_{30}$ was considered as non-ethical as it potentially delayed a new fluid challenge.

Patient characteristic, age, sex, height, weight, main diagnosis, and the New Simplified Acute Physiology Score II at admission, were collected.

The ventilator settings (tidal volume (VT), respiratory rate (RR), FiO2, positive-end expiratory pressure (PEEP), and plateau pressure (Pplat)) and the Score of Organ Failure Assessment (SOFA) were collected at patient inclusion and were not modified during study intervention.

Invasive mean arterial pressure (MAP) and heart rate (HR) were continuously monitored.

Transthoracic echocardiography (TTE) assessment was performed by experienced operator. Patients were preferentially assessed in semi-recumbent position that was not altered during the experiment. The cardiac function was assessed on a five chamber apical view. Stroke volume and its variations during the experiment 


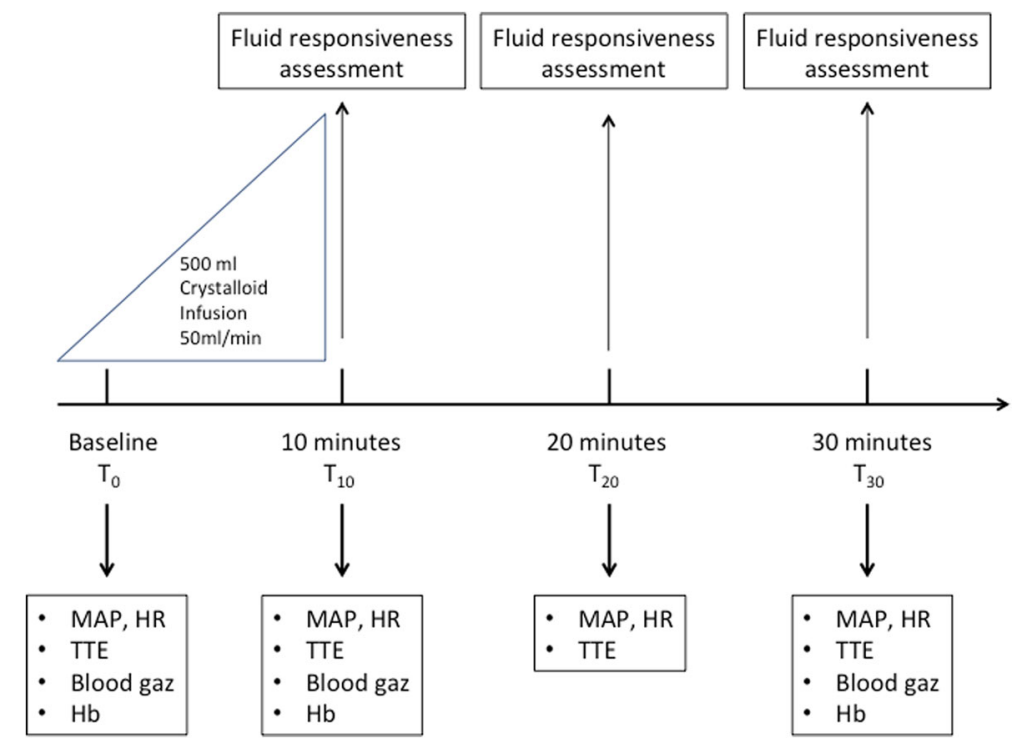

Fig. 1 Study design. MAP, mean arterial pressure (mmHg); HR, heart rate (beat per minute), TTE, transthoracic echocardiography; Hb, patient blood hemoglobin $(\mathrm{g} / \mathrm{dL})$

were assessed by maximal VTI and its variations over time [1]. The maximal subaortic VTI was recorded independently of the respiratory cycle. Left ventricular filling pressures and diastolic function were assessed by recording transmitral pulsed Doppler diastolic inflow ( $\mathrm{E}$ wave velocity $\left(\mathrm{cm} \mathrm{s}^{-1}\right)$, A wave velocity $\left(\mathrm{cm} \mathrm{s}^{-1}\right), \mathrm{E} / \mathrm{A}$ velocity ratio) coupled to tissue Doppler imaging at the lateral mitral annulus (Ea wave velocity $\left.\left(\mathrm{cm} \mathrm{s}^{-1}\right)\right)$. For right ventricular function assessment, the right to left surface telediastolic ventricular ratio and the tissue Doppler imaging at the lateral tricuspid annulus (tricuspid $\mathrm{S}$ wave velocity $\left(\mathrm{cm} \mathrm{s}^{-1}\right)$ ) were measured [17, 18]. MAP, HR, and TTE variables were collected at baseline $\left(T_{0}\right)$, at the end of fluid challenge $\left(T_{10}\right)$, and $10\left(T_{20}\right)$ and $20 \mathrm{~min}\left(T_{30}\right)$ after the end of fluid challenge.

Blood samples were withdrawn at $T_{0}, T_{10}$, and $T_{30}$ for measuring $\mathrm{P}_{\mathrm{a}} \mathrm{O}_{2}, \mathrm{P}_{\mathrm{a}} \mathrm{CO}_{2}, \mathrm{pH}, \mathrm{S}_{\mathrm{a}} \mathrm{O}_{2}$, central venous oxygen saturation $\left(\mathrm{S}_{\mathrm{cv}} \mathrm{O}_{2}\right)$, arterial lactate $\left(\mathrm{m} \mathrm{mol}^{-1}\right)$ and hemoglobin $\left(\mathrm{g} \mathrm{dl}^{-1}\right)$ concentrations.

\section{Statistical analysis}

The primary and secondary analyses were performed according to the intention-to-treat principle. A per-protocol analysis was also performed for the primary criteria by excluding patients for whom the fluid challenge protocol was not respected.

The primary endpoint was the rate of NR to fluid challenge at $T_{30}$ among the responders at $T_{10}$ (fluid responsiveness was defined by a $>15 \%$ VTI increase, corresponding to a $>15 \% \mathrm{SV}$ increase). This rate was estimated with its 95\% confidence interval and compared to a fixed proportion of $10 \%$ with a unilateral risk alpha.

We calculated that 69 responders to fluid challenge at $T_{10}$ were necessary to have a power of $80 \%$ to detect a rate of non-responders at $T_{30}$ greater than $10 \%$, with a unilateral alpha risk of $5 \%$. Under the hypothesis that $50 \%$ of patients would be responders at $T_{10}$, the inclusion of 138 patients was judged necessary. For taking a $5 \%$ rate of unusable data into account, 145 patients were included.

Quantitative data are expressed as mean and standard deviation (SD) or median and interquartile range (IQR), according to their distribution. Qualitative data are expressed as absolute number and frequency (\%).

Comparison between groups used, when appropriate, ANOVA or Kruskal-Wallis test for three group comparisons and student's T, Wilcoxon, chi-square, or Fisher's tests for two group comparisons. When multiple comparisons were performed, a Bonferroni correction was applied. A $p$ value $<0.05$ was considered as statistically significant. Statistical analysis was performed using $R$ software version 3.0.2 (R Development Core Team 2009, $\mathrm{R}$ Foundation for Statistical Computing, Vienna, Austria).

\section{Results}

\section{Patient characteristics and flow chart}

From May 20, 2014, to January 7, 2016, 143 out of 145 patients eligible with septic shock were included (Fig. 2). All patients received norepinephrine. Patient characteristics are shown in Table 1. Patient cardio-respiratory, biological, and echocardiographic parameters are shown in Table 2. 


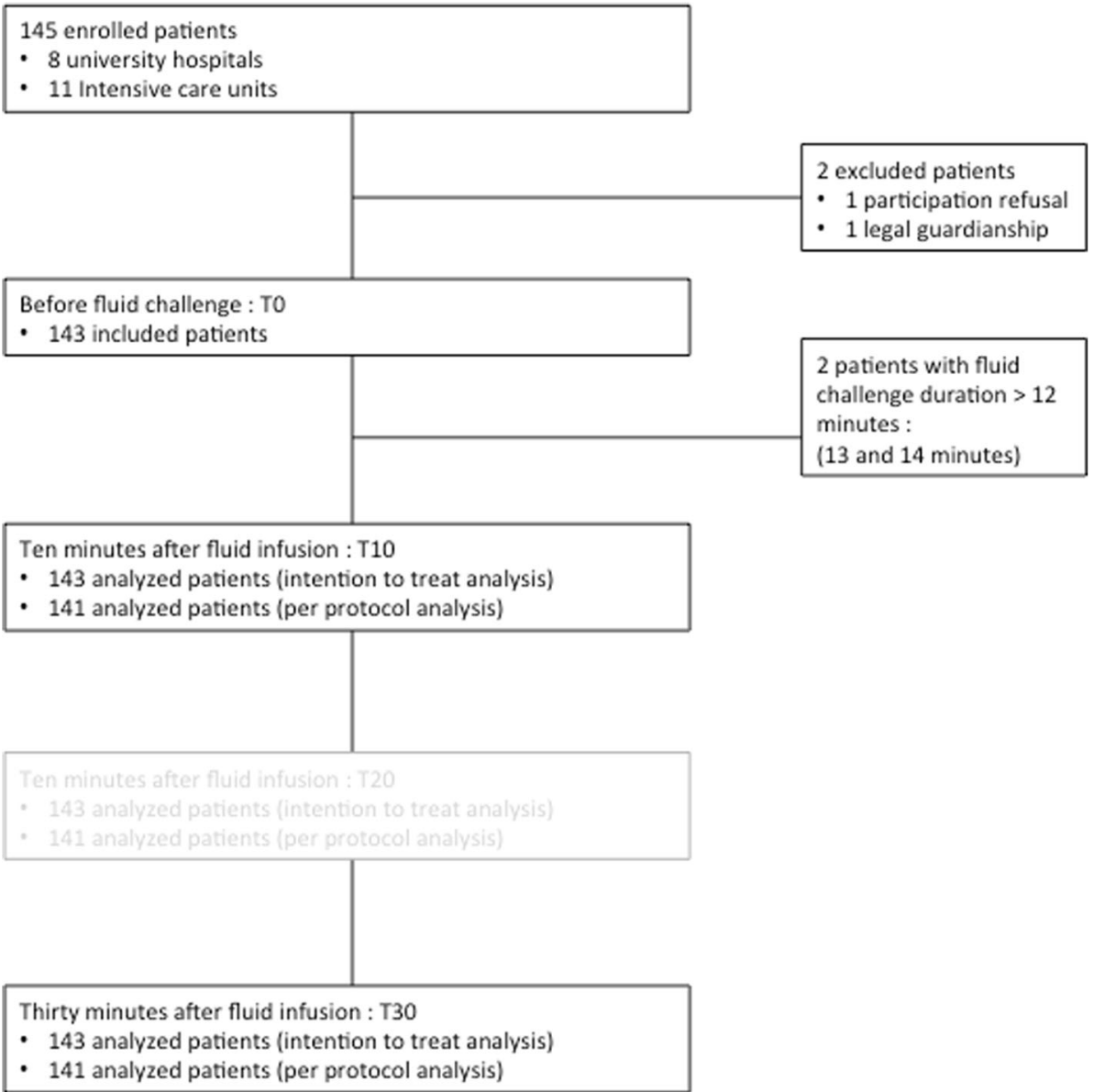

Fig. 2 Study flow chart

\section{Fluid challenge assessment}

Fluid challenge induced a $>15 \%$ increase in VTI in 76/143 patients (53\%) at $T_{10}$ (Fig. 3). Among these 76 responders, 37 changed their fluid responsiveness status from R to NR at $T_{30}(48.7 \%, 95 \% \mathrm{CI}=[37.2-60.3])$. These patients were defined as transient responders (TR). Among the 76 responders, $39(51.3 \%, 95 \% \mathrm{CI}=[39.6-62.8])$ remained responders $(\mathrm{R})$ at $T_{30}$. These patients were defined as persistent responders (PR) (Fig. 3). Among $67 \mathrm{NR}$ at $T_{10}$, only 4 became $\mathrm{R}$ at $T_{30}(6 \%, 95 \% \mathrm{CI}=[1.9-15.3])$. The per-protocol analysis was achieved on 141 patients, and results are comparable to the results of the intentionto-treat analysis presented above (percentage estimations do not differ more than $0.6 \%$ ). Hemodynamic and echocardiographic time profile of NR, TR, and PR are shown in Tables 3 and 4 (Additional file 1). The time course of VTI in NR, TR, and PR groups is shown in Fig. 4.

\section{Discussion}

\section{Key findings}

The present study assessing the short-term hemodynamic effects of FC in sepsis shows that half of the responders at the end of the FC are no longer responders 20 min later (Fig. 3). These findings led to describe three different profiles of fluid responsiveness: the NR for whom no fluid efficacy was observed over time, the PR exhibiting a positive and sustained response to FC over time, and the TR exhibiting initially a positive response to $\mathrm{FC}$ that was not maintained over time. The VTI course over time was significantly different between NR, PR, and TR $(p<0.001)$ (Fig. 4) as well as baseline VTI $(18.2 \pm 5.3 \mathrm{~cm}, 14.3 \pm 3.6$ $\mathrm{cm}, 16.2 \pm 4.9 \mathrm{~cm}$, respectively). We assume that VTI values at baseline (reflecting blood volume status) could help identifying transient and persistent fluid responders.

\section{Relationship with previous papers}

The time course of volume expansion after a fluid challenge has been poorly described. In experimental model, Guyton et al. demonstrated in normovolemic anesthetized dogs that fluid infusion increased by two to three times $\mathrm{CO}$ and mean circulatory pressure [19]. In this experiment, these two parameters returned to baseline values within 90 to $120 \mathrm{~min}$. This experiment shows that in normovolemic conditions and preserved systolic 
Table 1 Patient characteristics $(n=143)$

\begin{tabular}{|c|c|}
\hline Variables & \\
\hline Female & $50(35 \%)$ \\
\hline Age (years) & $64 \pm 14$ \\
\hline Weight (kg) & $75 \pm 20$ \\
\hline Height (cm) & $168 \pm 9$ \\
\hline BMI $\left(\mathrm{kg} \mathrm{m}^{-2}\right)$ & $26.8 \pm 7.1$ \\
\hline SAPS II score at admission & $53[43-63]$ \\
\hline SOFA score at inclusion & $10[8-12]$ \\
\hline \multicolumn{2}{|l|}{ Comorbidities ( $n, \%)$} \\
\hline Hypertension & $53(37 \%)$ \\
\hline Coronary artery disease & $24(17 \%)$ \\
\hline Cardiac heart failure & $5(4 \%)$ \\
\hline Diabetes mellitus & $17(12 \%)$ \\
\hline COPD & $17(12 \%)$ \\
\hline Creatinine clearance $<30 \mathrm{ml} \mathrm{min}^{-1}$ & $8(6 \%)$ \\
\hline \multicolumn{2}{|l|}{ Origin of sepsis $(n, \%)$} \\
\hline Pulmonary & $62(43 \%)$ \\
\hline Intra-abdominal & $58(41 \%)$ \\
\hline Urinary tract & $12(8 \%)$ \\
\hline Bacteremia & $7(5 \%)$ \\
\hline Miscellaneous & $15(11 \%)$ \\
\hline \multicolumn{2}{|c|}{$\begin{array}{l}\text { Continuous data are presented as the mean (SD) or median (IQR). Categorical } \\
\text { data are presented as counts (\%) } \\
\text { BMI body mass index, SAPS II Simplified Acute Physiology Score II, SOFA } \\
\text { Sequential Organ Failure Assessment, COPD chronic obstructive } \\
\text { pulmonary disease }\end{array}$} \\
\hline
\end{tabular}

function, the physiological response of cardiovascular system to fluid infusion is a transient increase in CO. A recent study including 20 patients with circulatory shock showed that hemodynamic effects of crystalloid infusion no longer last after $60 \mathrm{~min}$, even in patients that have been considered as responders immediately after fluid infusion [20]. In this study, the author's main hypothesis was that crystalloids infusion was systematically associated with capillary leak and subsequent decrease in plasma volume expansion over time. Similarly, in a recent randomized trial involving 200 postoperative hypovolemic patients, the infusion of lactated Ringer's solution significantly improved cardiac output at the end of infusion, but this effect totally disappeared at $120 \mathrm{~min}$ [21]. Therefore, such results suggest that the immediate response to fluid does not predict the persistence of fluid efficacy over time. This is a key issue as it is widely recommended to assess fluid responsiveness at the end of fluid infusion or functional manoeuver such as passive leg raising (PLR) test. It was previously demonstrated that the maximal hemodynamic effect of PLR is observed from 30 to $90 \mathrm{~s}$ after the onset of the test [22]. Analogous results were recently reported after a conventional fluid challenge $(250 \mathrm{ml}$ crystalloid infusion
Table 2 Patient clinical, biological, and echocardiographic parameters at baseline $(n=143)$

\begin{tabular}{|c|c|}
\hline \multicolumn{2}{|l|}{ Variables } \\
\hline Heart rate $(\mathrm{bpm})(\mathrm{MD}=0)$ & $94 \pm 24$ \\
\hline Mean arterial pressure $(\mathrm{mmHg})(\mathrm{MD}=0)$ & $74 \pm 12$ \\
\hline Tidal volume $(\mathrm{mL} / \mathrm{Kg})(\mathrm{MD}=0)$ & $6.0 \pm 1.0$ \\
\hline Respiratory rate $\left(\right.$ cycle $\left.\mathrm{min}^{-1}\right)(\mathrm{MD}=0)$ & $22[18-25]$ \\
\hline $\operatorname{PEEP}\left(\mathrm{cm} \mathrm{H}_{2} \mathrm{O}\right)(\mathrm{MD}=0)$ & $6[5-8]$ \\
\hline$P_{\text {plateau }}\left(\mathrm{cm} \mathrm{H}_{2} \mathrm{O}\right)(\mathrm{MD}=9)$ & 19 [17-23] \\
\hline Norepinephrine infusion rate $\left(\mu \mathrm{g} \mathrm{kg} \mathrm{min}^{-1}\right)$ & $0.41[0.22-0.95]$ \\
\hline Arterial blood lactate $\left(\mathrm{mMol} \mathrm{L}^{-1}\right)(\mathrm{MD}=5)$ & $1.95[1.3-3.55]$ \\
\hline $\mathrm{S}_{\mathrm{CV}} \mathrm{O}_{2}(\mathrm{MD}=58)$ & 77 [68-83] \\
\hline $\mathrm{pH}(\mathrm{MD}=2)$ & $7.34[7.25-7.40]$ \\
\hline $\mathrm{P}_{\mathrm{a}} \mathrm{O}_{2}(\mathrm{mmHg})(\mathrm{MD}=2)$ & 99 [79-128] \\
\hline $\mathrm{P}_{\mathrm{a}} \mathrm{CO}_{2}(\mathrm{mmHg})(\mathrm{MD}=3)$ & $40[35-46]$ \\
\hline Hemoglobin $\left(\mathrm{g} \mathrm{dL}^{-1}\right)(\mathrm{MD}=2)$ & $10.7[9.4-12.1]$ \\
\hline \multicolumn{2}{|l|}{ Estimated ejection fraction (MD = 7) } \\
\hline$<40 \%$ & $16(11 \%)$ \\
\hline$\geq 40 \%$ & $120(84 \%)$ \\
\hline VTI (cm) (MD = 0) & $16.6 \pm 5$ \\
\hline E wave $\left(\mathrm{m} \mathrm{s}^{-1}\right)(\mathrm{MD}=1)$ & $0.69 \pm 0.20$ \\
\hline A wave $\left(\mathrm{m} \mathrm{s}^{-1}\right)(\mathrm{MD}=3)$ & $0.74 \pm 0.23$ \\
\hline$E^{\prime}$ wave $\left(\mathrm{m} \mathrm{s}^{-1}\right)(\mathrm{MD}=2)$ & $0.1[0.07-0.13]$ \\
\hline S wave $\left(\mathrm{cm} \mathrm{s}^{-1}\right)(\mathrm{MD}=13)$ & $11.7 \pm 5.1$ \\
\hline E/A ratio $(M D=3)$ & $1.03 \pm 0.55$ \\
\hline E/E' ratio $(M D=3)$ & $7.0 \pm 3.7$ \\
\hline
\end{tabular}

Continuous data are presented as the mean (SD) or median (IQR). Categorical data are presented as counts (\%)

$M D$ missing data, $\mathrm{S}_{\mathrm{Cv}} \mathrm{O}_{2}$ central venous oxygen saturation

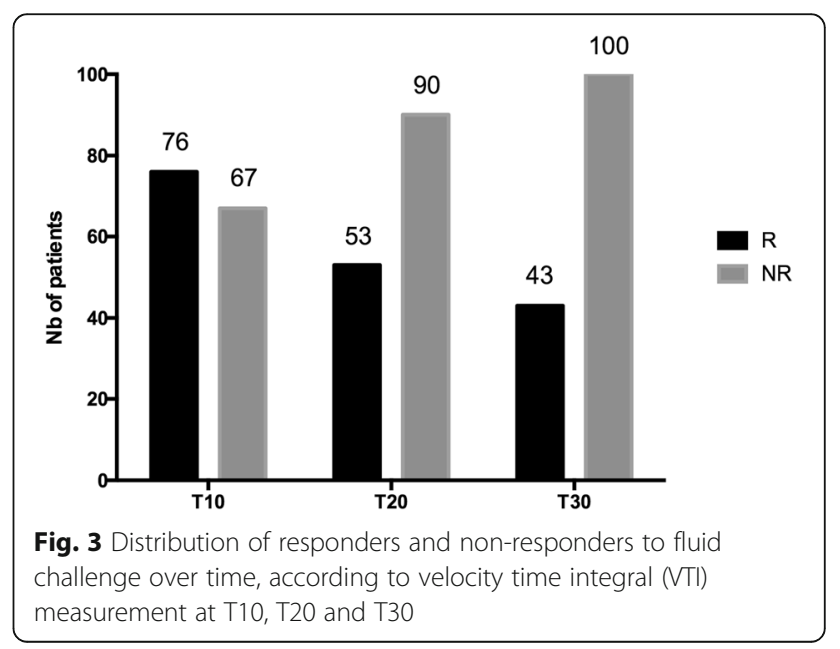


Table 3 Comparison of patient characteristics between non-responders (NR), persistent responders (PR), and transient responders (TR)

\begin{tabular}{|c|c|c|c|c|c|c|c|}
\hline Variables & $\operatorname{NR}(n=67)$ & $\mathrm{PR}(n=39)$ & $\operatorname{TR}(n=37)$ & $\begin{array}{l}p \text { value for } \\
\text { all groups }\end{array}$ & $\begin{array}{l}p \text { value } \\
\text { NR vs. PR }\end{array}$ & $\begin{array}{l}p \text { value } \\
\text { NR vs. TR }\end{array}$ & $\begin{array}{l}p \text { value } \\
\text { PR vs. TR }\end{array}$ \\
\hline Age (years) & $62.6 \pm 13.7$ & $67.7 \pm 14.1$ & $64.5 \pm 14.1$ & 0.19 & 0.07 & 0.50 & 0.33 \\
\hline SAPS $\|$ at admission & $48.5[42.3-57.8]$ & $58[48-73.5]$ & $55[45-62]$ & 0.053 & 0.017 & 0.23 & 0.29 \\
\hline SOFA at inclusion & $9[8-11.8]$ & 10 [9-13] & $10[7-11]$ & 0.34 & 0.14 & 0.86 & 0.33 \\
\hline Arterial lactate at baseline $(\mathrm{mMol} / \mathrm{l})$ & $1.8[1.3-3.1]$ & $2.55[1.33-5.43]$ & $1.9[1.1-3.45]$ & 0.16 & 0.10 & 0.78 & 0.08 \\
\hline ICU mortality rate & $25.4 \%$ & $46.2 \%$ & $37.8 \%$ & 0.08 & 0.048 & 0.27 & 0.62 \\
\hline Norepinephrine $\geq 0.5 \mathrm{\mu g} \mathrm{kg}^{-1} \mathrm{~min}^{-1}$ & $0.34[0.22-0.67]$ & $0.64[0.32-1.29]$ & $0.39[0.20-0.95]$ & 0.07 & 0.02 & 0.84 & 0.13 \\
\hline LVEF & & & & 0.88 & 1.00 & 0.76 & 0.73 \\
\hline$<40 \%$ & $7(11.1 \%)$ & $4(10.5 \%)$ & $5(14.3 \%)$ & & & & \\
\hline$\geq 40 \%$ & 56 (88.9\%) & 34 (89.5\%) & 30 (85.7\%) & & & & \\
\hline
\end{tabular}

Continuous data are presented as the mean (SD) or median (IQR). Categorical data are presented as counts (\%). For comparison of the NR, TR, and PR groups, a $p$ value $<0.05$ was considered as significant. For pairwise comparison, a $p$ value $<0.017$ was considered as significant (Bonferroni correction)

SAPS II Simplified Acute Physiology Score II, SOFA Sequential Organ Failure Assessment, ICU intensive care unit, LVEF left ventricular ejection fraction

over $5 \mathrm{~min}$ ) [23]. In this study involving 26 postoperative patients, the authors demonstrated that the maximal $\mathrm{CO}$ increase was observed $1 \mathrm{~min}$ after the end of fluid infusion [23]. Moreover, the effect of fluid infusion was dissipated in $10 \mathrm{~min}$ both in $\mathrm{R}$ and NR patients. Therefore, the available literature suggests that fluid efficacy is never prolonged.

Moreover, in the present study, we used crystalloids for FC according to international guidelines $[1,15]$. Several studies suggest that in normo- or slightly hypovolemic patients, the volume efficacy of crystalloids is closed to $20-25 \%$ [24] after $30 \mathrm{~min}$ of fluid infusion, due to a temporal shift of fluid toward interstitial compartment. This can explain the drop of VTI over time observed in TR that, in our hypothesis, are likely to be normovolemic. This hypothesis is supported by the fact that, even non-significant, the $\mathrm{E} / \mathrm{E}^{\prime}$ ratio is more elevated in NR and TR (7.9 and 6.6) as compared to PR (5.7) (Table 4).

Conversely to previous studies focusing on the time course of fluid effects, we observed that some patients exhibited a sustained response to fluid therapy that we called "persistent response to fluid therapy." In these patients, the hemodynamic values did not return to baseline $30 \mathrm{~min}$ after the start of the infusion. In PR, we could hypothesize that the efficacy of fluid is probably increased because of a significant drop in blood volume leading to very low values of hydrostatic pressure. Hahn and coworkers have nicely demonstrated that the volume efficacy of crystalloids was directly affected by blood volume status [14, 24]. In healthy volunteers undergoing blood removal, the elimination rate of a Ringer's solution from the blood compartment was 4-fold higher in volunteers with no blood removal as compared to the same volunteers experiencing a 900-ml blood withdrawal. This suggests that the fluid efficacy of crystalloids may be as high as 80 to $100 \%$ in case of absolute blood volume reduction [24-26]. As these results were mainly observed in a model of controlled hemorrhage in healthy volunteers, we cannot extrapolate to ICU patients, in whom a $80-100 \%$ fluid efficacy of crystalloids is unlikely to be observed.

It is unlikely that vasopressors can influence the type of fluid response, transient or persistent, in the present study as no difference was observed between TR and PR in terms of vasopressor doses.

Finally, in the present population with a majority of patients with normal LVEF (Table 2), the absolute VTI value at baseline is probably of particular importance for explaining the differences between TR, PR, and NR groups in terms of fluid responsiveness status. Figure 4 shows a significant difference at baseline VTI between the three groups. In the PR group, baseline VTI value is significantly lower $(14 \mathrm{~cm})$ than in TR and NR, suggesting that absolute VTI could help to detect PR.

\section{Implications of study findings}

Our results highlight that, among fluid responders, a few proportion of them have a sustained response to fluid. These findings enhance to closely test fluid responsiveness before administering large amounts of fluid $(500 \mathrm{ml})$ and to follow this response over time while looking at the efficacy of fluid infusion on organ dysfunction. Besides, fluid responsiveness should be assessed both at the end of fluid bolus and $30 \mathrm{~min}$ after the start in order to identify PR and TR. Further studies are necessary to identify if different fluid strategy should be applied in TR and PR.

\section{Study limitations}

We have some limitations to declare:

- First, the present study does not report any outcome endpoints. 
Table 4 Time-course of hemodynamic and echocardiographic variables according to fluid responsiveness status (non-responders (NR) $(n=67)$, persistent responders (PR) $(n=39)$, and transient responders (TR) $(n=37))$

\begin{tabular}{|c|c|c|c|c|c|}
\hline Variables & & $\mathrm{T}_{0}$ (baseline) & $\mathrm{T}_{10}$ & $\mathrm{~T}_{20}$ & $T_{30}$ \\
\hline \multirow[t]{3}{*}{$\overline{\mathrm{MAP}}(\mathrm{mmHg})$} & NR & $73 \pm 9.9$ & $77.7 \pm 11.3$ & $76.5 \pm 11.1$ & $76 \pm 11.7$ \\
\hline & PR & $75 \pm 15.2$ & $81.7 \pm 15.6$ & $82.6 \pm 14.8$ & $80.8 \pm 14.6$ \\
\hline & TR & $73.1 \pm 10.7$ & $81.4 \pm 13.2$ & $76.7 \pm 14.4$ & $75.9 \pm 12.6$ \\
\hline \multirow[t]{3}{*}{ SAP $(\mathrm{mmHg})$} & NR & $114.7 \pm 19.5$ & $123.8 \pm 22.2$ & $122.4 \pm 21.5$ & $120.3 \pm 21.7$ \\
\hline & PR & $112.2 \pm 22.8$ & $126.2 \pm 22.4$ & $125 \pm 21.4$ & $121.3 \pm 22$ \\
\hline & TR & $111.9 \pm 18.5$ & $127.3 \pm 21.6$ & $120.4 \pm 21.3$ & $118.9 \pm 20.8$ \\
\hline \multirow[t]{3}{*}{ DAP (mmHg) } & NR & $54.6 \pm 8.9$ & $57.3 \pm 9.8$ & $56.4 \pm 9.8$ & $56.1 \pm 9.8$ \\
\hline & $P R$ & $59.4 \pm 13$ & $62.1 \pm 12.2$ & $61.6 \pm 13.1$ & $60.7 \pm 12.2$ \\
\hline & TR & $55.2 \pm 8.8$ & $59 \pm 10.7$ & $56.6 \pm 11.5$ & $56.5 \pm 10.7$ \\
\hline \multirow[t]{3}{*}{ HR (bpm) } & NR & $93.5 \pm 22.1$ & $91.3 \pm 21.4$ & $90.3 \pm 22.8$ & $91.7 \pm 21.9$ \\
\hline & $P R$ & $92 \pm 25.9$ & $90.8 \pm 23.5$ & $91.7 \pm 24.6$ & $91.8 \pm 24.6$ \\
\hline & TR & $96.4 \pm 24.3$ & $93.3 \pm 22.3$ & $93.6 \pm 23.1$ & $94.5 \pm 23.6$ \\
\hline \multirow[t]{3}{*}{$\mathrm{EtCO}_{2}(\mathrm{mmHg})$} & NR & $32.2 \pm 6.2$ & $31.7 \pm 5.6$ & $31.6 \pm 5.7$ & $31.7 \pm 5.8$ \\
\hline & $P R$ & $29.9 \pm 5.6$ & $29.8 \pm 5.4$ & $30.3 \pm 5.6$ & $29.9 \pm 5.4$ \\
\hline & TR & $31 \pm 6.6$ & $31.9 \pm 6.6$ & $32.1 \pm 7$ & $32 \pm 7.4$ \\
\hline \multirow[t]{3}{*}{ VTI (cm) } & NR & $18.2 \pm 5.3$ & $19 \pm 5.8$ & $18.8 \pm 5.9$ & $18.6 \pm 5.9$ \\
\hline & $P R$ & $14.3 \pm 3.6$ & $19.5 \pm 4.9$ & $18.6 \pm 5.2$ & $18.9 \pm 5.3$ \\
\hline & TR & $16.2 \pm 4.9$ & $20.4 \pm 5.5$ & $18.1 \pm 5.4$ & $17.3 \pm 5.4$ \\
\hline \multirow[t]{3}{*}{ E wave $\left(\mathrm{m} \mathrm{s}^{-1}\right)$} & NR & $0.7 \pm 0.2$ & $0.9 \pm 0.2$ & $0.8 \pm 0.2$ & $0.8 \pm 0.2$ \\
\hline & $P R$ & $0.6 \pm 0.2$ & $0.8 \pm 0.2$ & $0.7 \pm 0.2$ & $0.7 \pm 0.2$ \\
\hline & TR & $0.7 \pm 0.2$ & $0.8 \pm 0.2$ & $0.7 \pm 0.2$ & $0.7 \pm 0.2$ \\
\hline \multirow[t]{3}{*}{ A wave $\left(\mathrm{m} \mathrm{s}^{-1}\right)$} & NR & $0.7 \pm 0.2$ & $0.8 \pm 0.2$ & $0.8 \pm 0.2$ & $0.8 \pm 0.2$ \\
\hline & $P R$ & $0.8 \pm 0.2$ & $0.8 \pm 0.2$ & $0.8 \pm 0.2$ & $0.8 \pm 0.2$ \\
\hline & TR & $0.7 \pm 0.3$ & $0.8 \pm 0.3$ & $0.8 \pm 0.2$ & $0.8 \pm 0.3$ \\
\hline \multirow[t]{3}{*}{ E/A ratio } & NR & $1.1 \pm 0.4$ & $1.2 \pm 0.4$ & $1.1 \pm 0.4$ & $1.1 \pm 0.4$ \\
\hline & $P R$ & $0.9 \pm 0.4$ & $1 \pm 0.4$ & $1 \pm 0.5$ & $1 \pm 0.5$ \\
\hline & TR & $1.1 \pm 0.8$ & $1.2 \pm 1.2$ & $1 \pm 0.3$ & $0.9 \pm 0.3$ \\
\hline \multirow[t]{3}{*}{$E^{\prime}$ wave $\left(\mathrm{m} \mathrm{s}^{-1}\right)$} & NR & $0.1 \pm 0.1$ & $0.2 \pm 0.2$ & $0.2 \pm 0.3$ & $0.1 \pm 0.2$ \\
\hline & PR & $0.2 \pm 0.3$ & $0.3 \pm 0.4$ & $0.3 \pm 0.4$ & $0.2 \pm 0.4$ \\
\hline & TR & $0.2 \pm 0.2$ & $0.1 \pm 0.1$ & $0.1 \pm 0.2$ & $0.1 \pm 0.2$ \\
\hline \multirow[t]{3}{*}{ E/E' ratio } & NR & $7.9 \pm 4$ & $8 \pm 4.2$ & $7.8 \pm 3.7$ & $8.3 \pm 3.9$ \\
\hline & $P R$ & $5.7 \pm 3.4$ & $6.5 \pm 3.6$ & $6 \pm 3.6$ & $6.4 \pm 3.4$ \\
\hline & TR & $6.6 \pm 3.2$ & $8 \pm 3$ & $7.7 \pm 3.3$ & $7.4 \pm 3.5$ \\
\hline \multirow[t]{3}{*}{$\mathrm{ScVO}_{2}(\%)$} & NR & $74 \pm 12.1$ & $74.4 \pm 11.7$ & NA & $74 \pm 12.1$ \\
\hline & $P R$ & $76.1 \pm 11.3$ & $76.4 \pm 8.2$ & NA & $76.1 \pm 11.3$ \\
\hline & TR & $78.5 \pm 8.5$ & $79.1 \pm 9.2$ & NA & $78.5 \pm 8.5$ \\
\hline \multirow[t]{3}{*}{ Arterial lactate $\left(\mathrm{mmol} \mathrm{L}^{-1}\right)$} & NR & $2.7 \pm 2.4$ & $2.7 \pm 2.8$ & NA & $2.6 \pm 2.8$ \\
\hline & $P R$ & $3.4 \pm 2.6$ & $3.0 \pm 2.0$ & NA & $3.2 \pm 2.1$ \\
\hline & TR & $2.6 \pm 2.1$ & $2.3 \pm 1.9$ & NA & $2.5 \pm 2.1$ \\
\hline
\end{tabular}

Continuous data are presented as the mean $\pm S D$

$N R$ non-responders, $T R$ transient responders, $P R$ persistent responders, MAP mean arterial pressure, $S A P$ systolic arterial pressure, $D A P$ diastolic arterial pressure, $H R$ heart rate, EtCO2 end tidal $\mathrm{CO}_{2}$, VTI sub-aortic velocity time integral, $\mathrm{SCVO}_{2}$ central venous oxygen saturation 


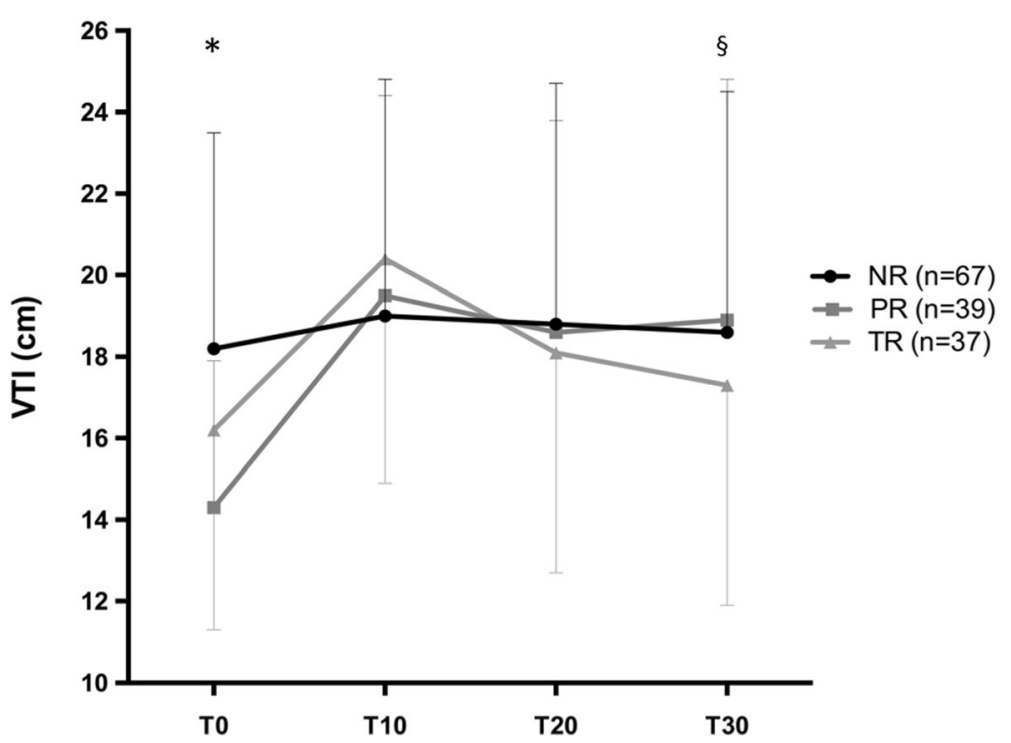

Fig. 4 Velocity time integral (VTI) course over time in non-responders (NR), transient responders (TR), and persistent responders (PR). ${ }^{*} D i f f e r e n c e$ between VTI value at baseline between NR, TR, and NR groups $(p=0.0003)$. ${ }^{\circledR}$ Significant interaction between time and groups $(p<0.0001)$ : stability of VTI over time in the NR group, VTI increase from $T_{0}$ to $T_{10}$, and subsequent decrease from T10 to T30 in TR and PR groups, with crossing curves between $T_{10}$ and $T_{20}$

- Second, one could argue that MAP and $\mathrm{ScvO}_{2}$ were in normal ranges at baseline, suggesting adequate blood volume and cardiac output, and ruling out indication of fluid infusion. However, during sepsis, $\mathrm{SvO}_{2}$ can be elevated due to microcirculatory alterations and may not reflect adequate tissue oxygenation explaining that fluid challenge has been performed despite normal $\mathrm{SvO} 2$ value in the present study. Similarly, fluid challenge has also been performed despite a mean $74 \mathrm{mmHg}$ MAP value at baseline as normal MAP does not rule out potential excess of norepinephrine associated with occult hypovolemia.

Third, it could be objected that performing fluid responsiveness tests (such as dynamic indices or PLR test) before administering a 500-mL fluid challenge would have been more suitable in order to limit undue fluid infusion. Despite such maneuvers are very informative, they are used in less than $15 \%$ of patients in large recent cohort studies $[8,9]$. In this pragmatic trial, the aim was to describe the evolution of fluid responsiveness over time for current practices.

We decided to use TTE to assess the response to fluid challenge even though some authors do not consider TTE as a valuable tool to assess fluid responsiveness [27]. However, guidelines on hemodynamic monitoring and a recent report consider TTE as reliable as thermodilution to assess $\mathrm{CO}[1,28]$. The reported intra- and inter-observer variability for VTI (aortic or pulmonary) measurement is closed to 5 to $8 \%$ with an intraclass correlation coefficient of 0.94 [12, 29].

\section{Conclusion}

This study shows that $51.3 \%$ of initial responders have a persistent response to fluid $30 \mathrm{~min}$ after the beginning of fluid infusion and only $41.3 \%$ have a transient response. These findings highlight that fluid responsiveness is time-dependent and that the issue of optimal timing needs to be addressed in future studies.

\section{Additional file}

Additional file 1: Sub-aortic velocity time integral (VTI) individual values. a In persistent responders. b In non-responders. c In transient responders. (PDF $190 \mathrm{~kb}$ )

\section{Acknowledgements}

The authors thank Guillaume Louart, Audrey Ambert, Loubna Elotmani, and Sophie Lloret for their help in data collection.

\section{Funding}

Support was provided solely from institutional sources.

\section{Availability of data and materials}

The datasets used and/or analyzed during the current study are available from the corresponding author on reasonable request.

\section{Authors' contributions}

$C R, L M, J Y L$, and $B L$ have conceived the study, checked all inclusions, and have wrote the manuscript. LZ, JMC, YM, GP, RC, JSF, ID, HQ, and KL have included patients, have substantially reviewed the manuscript, and have 
given their approval for the final version. CDM has participated to the conception of the study, has performed the statistical analysis, and has given his approval for the final version. All authors read and approved the final manuscript.

\section{Ethics approval and consent to participate}

Written consent prior to enrolment or in permitted instances, delayed participant or legal surrogate written consent following enrolment was obtained. This study was approved by the local ethic committee (Comité de Protection des Personnes \#2014.02.06, \#ID_RCB 2013-A01702-43).

\section{Consent for publication}

Not applicable.

\section{Competing interests}

The authors declare that they have no competing interests.

\section{Publisher's Note}

Springer Nature remains neutral with regard to jurisdictional claims in published maps and institutional affiliations.

\begin{abstract}
Author details
${ }^{1}$ Department of Anesthesiology and Intensive Care, Pain and Emergency Medicine, Nîmes-Caremeau University Hospital, Univ Montpellier, Place du Professeur Robert Debré, 30029 Nîmes Cedex 9, France. ²Physiology Department. EA 2992, Faculty of Medicine, Univ Montpellier, Montpellier-Nimes University, Nîmes, France. ${ }^{3}$ Department of Anesthesiology and Intensive Care Medicine, University Hospital of Marseille, 13000 Marseille, France. ${ }^{4}$ Department of Biostatistics Epidemiology and Medical information, Nîmes-Caremeau University Hospital, Univ Montpellier, Place du Professeur Robert Debré, 30029 Nîmes Cedex 9, France. ${ }^{5}$ Department of Anesthesiology and Intensive Care Medicine, University Hospital of Nantes, 44000 Nantes, France. ${ }^{6}$ Medical Intensive Care unit, University Hospital of Besançon, 25030 Besançon, France. ${ }^{7}$ Department of Anesthesiology and Intensive Care Medicine, University Hospital of Clermont-Ferrand, 63000 Clermont-Ferrand, France. ${ }^{8}$ Department of Anesthesiology and Intensive Care Medicine, University Hospital of Amiens, 80000 Amiens, France. ${ }^{9}$ Department of Anesthesiology and Intensive Care Medicine, University Hospital of Caen, 14033 Caen, France. ${ }^{10}$ Department of Anesthesiology and Intensive Care Medicine, University Hospital of Nice, 06000 Nice, France. ${ }^{11}$ Aix Marseille University, INSERM1263, INRA1260, C2VN, Marseille, France.
\end{abstract}

\section{Received: 5 December 2018 Accepted: 17 April 2019}

\section{Published online: 16 May 2019}

\section{References}

1. Cecconi M, De Backer D, Antonelli M, Beale R, Bakker J, Hofer C, Jaeschke R, Mebazaa A, Pinsky MR, Teboul JL, et al. Consensus on circulatory shock and hemodynamic monitoring. Task force of the European Society of Intensive Care Medicine. Intensive Care Med. 2014:40(12):1795-815

2. Garzotto F, Ostermann M, Martin-Langerwerf D, Sanchez-Sanchez M, Teng J, Robert R, Marinho A, Herrera-Gutierrez ME, Mao HJ, Benavente D, et al. The dose response multicentre investigation on fluid assessment (DoReMIFA) in critically ill patients. Crit Care. 2016:20(1):196

3. Teixeira C, Garzotto F, Piccinni P, Brienza N, lannuzzi M, Gramaticopolo S, Forfori F, Pelaia P, Rocco M, Ronco C, et al. Fluid balance and urine volume are independent predictors of mortality in acute kidney injury. Crit Care. 2013;17(1):R14

4. Frazee E, Kashani K. Fluid Management for critically ill patients: a review of the current state of fluid therapy in the intensive care unit. Kidney Dis (Basel). 2016;2(2):64-71

5. Teboul JL, Saugel B, Cecconi M, De Backer D, Hofer CK, Monnet X, Perel A, Pinsky MR, Reuter DA, Rhodes A, et al. Less invasive hemodynamic monitoring in critically ill patients. Intensive Care Med. 2016:42(9):1350-9.

6. Monnet $X$, Teboul JL. Assessment of volume responsiveness during mechanical ventilation: recent advances. Crit Care. 2013;17(2):217.

7. Bentzer P, Griesdale DE, Boyd J, MacLean K, Sirounis D, Ayas NT. Will this hemodynamically unstable patient respond to a bolus of intravenous fluids? JAMA. 2016;316(12):1298-309.
8. Cecconi M, Hofer C, Teboul JL, Pettila V, Wilkman E, Molnar Z, Della Rocca G, Aldecoa C, Artigas A, Jog S, et al. Fluid challenges in intensive care: the FENICE study: a global inception cohort study. Intensive Care Med. 2015:41(9):1529-37.

9. Boulain T, Boisrame-Helms J, Ehrmann S, Lascarrou JB, Bougle A, Chiche A, Lakhal K, Gaudry S, Perbet S, Desachy A, et al. Volume expansion in the first 4 days of shock: a prospective multicentre study in 19 French intensive care units. Intensive Care Med. 2015;41(2):248-56.

10. Thanachartwet $V$, Wattanathum A, Sahassananda D, Wacharasint $P$, Chamnanchanunt $S$, Khine Kyaw E, Jittmittraphap A, Naksomphun M, Surabotsophon M, Desakorn V. Dynamic measurement of hemodynamic parameters and cardiac preload in adults with dengue: a prospective observational study. PLoS One. 2016:11(5):e0156135.

11. Vincent JL, Weil MH. Fluid challenge revisited. Crit Care Med. 2006;34(5): $1333-7$

12. Muller L, Toumi M, Bousquet PJ, Riu-Poulenc B, Louart G, Candela D, Zoric L, Suehs C, de La Coussaye JE, Molinari N, et al. An increase in aortic blood flow after an infusion of $100 \mathrm{ml}$ colloid over 1 minute can predict fluid responsiveness: the mini-fluid challenge study. Anesthesiology. 2011;115(3):541-7.

13. Mahjoub Y, Benoit-Fallet H, Airapetian N, Lorne E, Levrard M, Seydi AA, Amennouche N, Slama M, Dupont H. Improvement of left ventricular relaxation as assessed by tissue Doppler imaging in fluid-responsive critically ill septic patients. Intensive Care Med. 2012;38(9):1461-70.

14. Chappell D, Jacob M, Hofmann-Kiefer K, Conzen P, Rehm M. A rational approach to perioperative fluid management. Anesthesiology. 2008;109(4):723-40.

15. Dellinger RP, Levy MM, Rhodes A, Annane D, Gerlach H, Opal SM, Sevransky JE, Sprung CL, Douglas IS, Jaeschke R, et al. Surviving Sepsis Campaign: international guidelines for management of severe sepsis and septic shock, 2012. Intensive Care Med. 2013;39(2):165-228.

16. Michard F, Teboul JL. Predicting fluid responsiveness in ICU patients: a critical analysis of the evidence. Chest. 2002;121(6):2000-8.

17. Rudski LG, Lai WW, Afilalo J, Hua L, Handschumacher MD, Chandrasekaran K, Solomon SD, Louie EK, Schiller NB. Guidelines for the echocardiographic assessment of the right heart in adults: a report from the American Society of Echocardiography endorsed by the European Association of Echocardiography, a registered branch of the European Society of Cardiology, and the Canadian Society of Echocardiography. J Am Soc Echocardiography. 2010;23(7):685-713 quiz 786-688.

18. Harjola VP, Mebazaa A, Celutkiene J, Bettex D, Bueno H, Chioncel O, CrespoLeiro MG, Falk V, Filippatos G, Gibbs S, et al. Contemporary management of acute right ventricular failure: a statement from the Heart Failure Association and the Working Group on Pulmonary Circulation and Right Ventricular Function of the European Society of Cardiology. Eur J Heart Fail. 2016;18(3):226-41

19. Prather JW, Taylor AE, Guyton AC. Effect of blood volume, mean circulatory pressure, and stress relaxation on cardiac output. Am J Phys. 1969;216(3): 467-72.

20. Nunes TS, Ladeira RT, Bafi AT, de Azevedo LC, Machado FR, Freitas FG. Duration of hemodynamic effects of crystalloids in patients with circulatory shock after initial resuscitation. Ann Intensive Care. 2014;4: 25.

21. Gondos T, Marjanek Z, Ulakcsai Z, Szabo Z, Bogar L, Karolyi M, Gartner $B$, Kiss K, Havas A, Futo J. Short-term effectiveness of different volume replacement therapies in postoperative hypovolaemic patients. Eur J Anaesthesiol. 2010;27(9):794-800.

22. Monnet $X$, Teboul JL. Passive leg raising. Intensive Care Med. 2008;34(4):659-63.

23. Aya HD, Ster IC, Fletcher N, Grounds RM, Rhodes A, Cecconi M. Pharmacodynamic analysis of a fluid challenge. Crit Care Med. 2016; 44(5):880-91.

24. Hahn RG. Volume kinetics for infusion fluids. Anesthesiology. 2010;113(2):470-81.

25. Drobin D, Hahn RG. Volume kinetics of Ringer's solution in hypovolemic volunteers. Anesthesiology. 1999;90(1):81-91.

26. Hahn RG. Why crystalloids will do the job in the operating room. Anaesthesiol Intensive Ther. 2014;46(5):342-9.

27. Wetterslev M, Haase N, Johansen RR, Perner A. Predicting fluid responsiveness with transthoracic echocardiography is not yet evidence based. Acta Anaesthesiol Scand. 2013;57(6):692-7.

28. Mercado P, Maizel J, Beyls C, Titeca-Beauport D, Joris M, Kontar L, Riviere A, Bonef $\mathrm{O}$, Soupison T, Tribouilloy $\mathrm{C}$, et al. Transthoracic 
echocardiography: an accurate and precise method for estimating cardiac output in the critically ill patient. Crit Care. 2017;21(1):136.

29. Gavaud A, Nguyen LS, Caubel A, Grillet G, Donal E, Belliard G. Respiratory variability of pulmonary velocity-time integral as a new gauge of fluid responsiveness for mechanically ventilated patients in the ICU. Crit Care Med. 2019;47(4):e310-6

Ready to submit your research? Choose BMC and benefit from:

- fast, convenient online submission

- thorough peer review by experienced researchers in your field

- rapid publication on acceptance

- support for research data, including large and complex data types

- gold Open Access which fosters wider collaboration and increased citations

- maximum visibility for your research: over $100 \mathrm{M}$ website views per year

At $B M C$, research is always in progress.

Learn more biomedcentral.com/submissions 